\title{
A comparative study on antioxidant activity of different parts of lotus (Nelumbo nuficera Gaertn) rhizome
}

\author{
Dongmei YANG ${ }^{1 *}$, Qian ZHANG ${ }^{1}$, Guoping REN ${ }^{1}$, Tiejin YING ${ }^{2}$
}

\begin{abstract}
In this study, the antioxidant activities of different parts of lotus (Nelumbo nuficera Gaertn) rhizome were compared. The total phenolic content of lotus rhizome was determined, and Ferric reducing antioxidant power (FRAP) assay, 1,1-diphenyl-2-picrylhydrazyl hydrate (DPPH) radical-scavenging assay and $\beta$-carotene-linoleic acid assay were performed to assess the antioxidant activity of lotus rhizome. Results showed that there was a significant difference in total phenolic content and antioxidant activity between any two of four parts of lotus rhizome. The order of total phenolic content and antioxidant activity in different parts of lotus rhizome was as follows: peel of old lotus rhizome $>$ peel of young lotus rhizome $>$ flesh of old lotus rhizome $>$ flesh of young lotus rhizome. The total phenol content is significantly positive correlated with the antioxidant activity in different parts of lotus rhizome. This study has provided a basis for further exploring the antioxidant components in lotus rhizome.
\end{abstract}

Keywords: lotus rhizome; antioxidant activity; FRAP; DPPH; $\beta$-carotene bleaching assay.

Practical Application: The total phenol content is significantly positively correlated with the antioxidant activity in different parts of lotus rhizome. This study has significant importance for further developing the products related to lotus rhizome

\section{Introduction}

Lotus (Nelumbo nucifera Gaertn, N. nuficera) is an ornamental plant and dietary staple in Eastern Asia, particularly in China ( $\mathrm{Hu}$ \& Skibsted, 2002). All parts of N. nuficera are used as oriental medicine for various medicinal purposes (Kashiwada et al., 2005). The seed of N. nucifera is used as diuretic and cooling agent, antiemetic and antidote in the treatment of tissue inflammation and cancer (Chopra et al., 1956; Liu et al., 2004). The leaf of $N$. nucifera is considered the best for "over-coming body heat", and stopping bleeding (Bensky et al., 2004), and it is used as a drug for hematemesis, epistaxis, hemoptysis, hematuria and metrorrhagia (Ono et al., 2006). In China, the lotus rhizome can be cooked into different dishes or eating raw as a common vegetable. Especially, it has been applied in Chinese herbal prescriptions to alleviate tissue inflammation, cancer, and liver cirrhosis for a long time (Chopra et al., 1956).

It is reported that the extract of lotus rhizome exhibits high antioxidative capacity (Hu \& Skibsted, 2002), and the mian antioxidative compositions in lotus rhizome are phenolics including dopa, catechol, gallic acid, D-(+)-catechin and L-(-)-epicatechin (Wang et al., 2004). In our previous study (Yang et al., 2007), the antioxidant activities of lotus rhizome extract obtained with solvent of different polarity are determined. It is found that, all extracts obtained with different solvents exhibit higher antioxidant activity than ascorbic acid. Furthermore, the solvent property can significantly affect the yield, total phenolic content and antioxidant activity of extract. Very few data on antioxidant activity of lotus rhizome with different parts and different maturity levels are available. The aim of this work was to evaluate the antioxidant activity of flesh of young lotus rhizome, peel of young lotus rhizome, flesh of old lotus rhizome and peel of old lotus rhizome. The water content and total phenolic content of different parts of lotus rhizome were determined. Ferric reducing antioxidant power (FRAP) assay, 1,1-diphenyl-2-picrylhydrazyl hydrate (DPPH) radical scavenging assay and $\beta$-carotene-linoleic acid assay were conducted to assess the antioxidant activity of lotus rhizome.

\section{Materials and methods}

\subsection{Materials and reagents}

Lotus rhizome was purchased from Yiwu (Zhejiang, China) and washed by water. The parts with relatively large size in the middle (old lotus rhizome) and the parts with relatively small size at the front (young lotus rhizome) were cut down. The peel and flesh of old lotus rhizome and young lotus rhizome were prepared for use. 1,1-diphenyl-2-picrylhydrazyl (DPPH), $\beta$-carotene Folin-Ciocalteu reagent, gallic acid, linoleic acid and polyoxyethylene sorbitan monopalmitate (Tween40) were obtained from Sigma-Aldrich (Saint Louis, USA). All other chemicals used were of analytical grade.

\subsection{Extraction method}

Lotus rhizome sample ( $2 \mathrm{~g}$ ) was put in a mortar. $8 \mathrm{~mL}$ of $80 \%$ ethanol aqueous solution was added. The mixture was homogenated, then frozen centrifugated at $10,000 \mathrm{x}$ g for $15 \mathrm{~min}$. The supernatant was separated to obtain the sample solution for use. 


\subsection{Determination of total phenolic content}

Determination of total phenol content was carried out using a Folin-Ciocalteu method according to Slinkard \& Singleton's study (1997) with some modifications. $0.1 \mathrm{~mL}$ of Folin-Ciocalteu reagent and proper amount of sample solution were added in a flask. The flask was shaken up to mix the solutions thoroughly. After $3 \mathrm{~min}, 0.3 \mathrm{~mL}$ of $\mathrm{Na}_{2} \mathrm{CO}_{3}(2 \%)$ was added. The solutions were mixed again and left at room temperature for $2 \mathrm{~h}$. The absorbance was measured at $765 \mathrm{~nm}$ using a UV-Vis spectrophotometer. Total phenolic content of sample was calculated with a linear regression equation obtained from gallic acid standard curve: Absorbance $=8.3886 \times$ gallic acid $(\mu \mathrm{g})-0.0114$. Results were expressed as milligrams of gallic acid equivalent (GAE) per $100 \mathrm{~g}$ of lotus rhizome.

\subsection{Determination of FRAP value}

According to the method described by Benzie \& Strain (1996), $20 \mu \mathrm{L}$ of sample solution was added to $1.8 \mathrm{~mL}$ of FRAP reagent which was prepared by mixing $25 \mathrm{~mL}$ of sodium acetate buffer solution $(0.3 \mathrm{M}), 2.5 \mathrm{~mL}$ of TPTZ $(10 \mathrm{mM})$, $2.5 \mathrm{~mL}$ of $\mathrm{FeCl}_{3}(20 \mathrm{mM})$, and incubated at $37{ }^{\circ} \mathrm{C}$ for $30 \mathrm{~min}$. The absorbance of solutions was measured at $593 \mathrm{~nm}$ using a UV-Vis spectrophotometer. With $\mathrm{FeSO}_{4}$ solution $(1 \mathrm{mM})$ as the standard, FRAP value of sample was expressed as mmol of $\mathrm{Fe}(\mathrm{II})$ per $100 \mathrm{~g}$ of lotus rhizome, using linear calibration obtained with different concentrations of $\mathrm{FeSO}_{4}$.

\subsection{Determination of DPPH radical scavenging capacity}

Scavenging activity on DPPH radicals was measured according to the method of Moreno et al. (1998) with some modifications. $3.0 \mathrm{~mL}$ of ethanol solution of DPPH was added to $20 \mu \mathrm{L}$ of sample solution. The solutions were mixed thoroughly. After $3 \mathrm{~min}$, absorbance of the solutions was measured at $517 \mathrm{~nm}$ using a UV-Vis spectrophotometer. $80 \%$ ethanol was used as control. The DPPH radical scavenging activity of each sample was calculated by the DPPH inhibition (absorbance decrease) according to the following formula: $\mathrm{DPPH}$ inhibiton $(\%)=100^{*}\left(\mathrm{~A}_{\text {control }}-\mathrm{A}_{\text {sample }}\right) / \mathrm{A}_{\text {control }}(\mathrm{A}$ : absorbance $)$.

\subsection{Determination of antioxidant activity by $\beta$-carotene bleaching method}

Prevention of oxidative loss of $\beta$-carotene in a $\beta$-carotene/linoleic acid emulsion was used to assess the antioxidant ability of lotus rhizome according to the method of Moure et al. (2000). $2.0 \mathrm{mg}$ of $\beta$-carotene was dissolved in $10 \mathrm{~mL}$ chloroform, and $1.0 \mathrm{~mL}$ of the $\beta$-carotene solution was mixed with $20 \mathrm{mg}$ of purified linoleic acid and $200 \mathrm{mg}$ of Tween 40 in a round-bottom flask, then chloroform was removed in a rotary vacuum evaporator. After evaporation, $50 \mathrm{~mL}$ of distilled water was added and the mixture was stirred in a sonicator. $400 \mu \mathrm{L}$ of sample solution was added to $9.6 \mathrm{~mL}$ of $\beta$ - carotene/linoleic acid emulsion. $80 \%$ ethanol was used as control. Absorbance at $470 \mathrm{~nm}$ was immediately recorded after addition of sample. The vials were then gently capped and placed at $50{ }^{\circ} \mathrm{C}$ in a water bath. The absorbance was determined every $20 \mathrm{~min}$ until $120 \mathrm{~min}$. Antioxidant activity coefficient (AAC) was measured in terms of successful bleaching of $\beta$-carotene by using a slightly modified version of the formula: $\mathrm{AAC}=1000^{\star}\left(\mathrm{A}_{\text {Sample }(120 \mathrm{~min})}-\mathrm{A}_{\text {Control (120 min })}\right) /\left(\mathrm{A}_{\text {Control (0 min })}-\mathrm{A}_{\text {Control }}\right.$ $(120 \mathrm{~min})$ (A: absorbance).

\subsection{Statistical analysis}

All analyses were run in triplicates and results averaged. Statistical analyses were performed with the Excel and SPSS software package. $P<0.05$ was considered as statistically significant.

\section{Results and discussion}

\subsection{Water content of different parts of lotus rhizome}

As shown in Figure 1, the water contents in different parts of lotus rhizome were different. The water content in peel of lotus rhizome was lower than that in flesh. Meanwhile, the water content of more mature tissue (old lotus rhizome) was lower than that of relative immature tissue (young lotus rhizome). The order of water content in different parts of lotus rhizome was as follows: flesh of young lotus rhizome $(92.57 \%)>$ peel of young lotus rhizome $(92.16 \%)>$ flesh of old lotus rhizome $(84.79 \%)>$ peel of old lotus rhizome $(82.74 \%)$.

\subsection{Total phenolic content of different parts of lotus rhizome}

Total phenolic content of different parts of lotus rhizome was shown in Figure 2. There was a significant difference in any two of four parts of lotus rhizome. The total phenolic content in peel of lotus rhizome was higher than that in flesh, and the total phenolic content in old lotus rhizome was higher than that in young lotus rhizome. The order of total phenolic content in different parts of lotus rhizome was as follows: peel of old lotus rhizome $>$ peel of young lotus rhizome $>$ flesh of old lotus rhizome $>$ flesh of young lotus rhizome. The highest phenolic content of peel of old lotus rhizome reached $340.7 \mathrm{mg}$ GAE/100g lotus rhizome which was three times of the least total phenolic content of flesh of young lotus rhizome (88.7 mg GAE/100g lotus rhizome). These results were in concordance with the

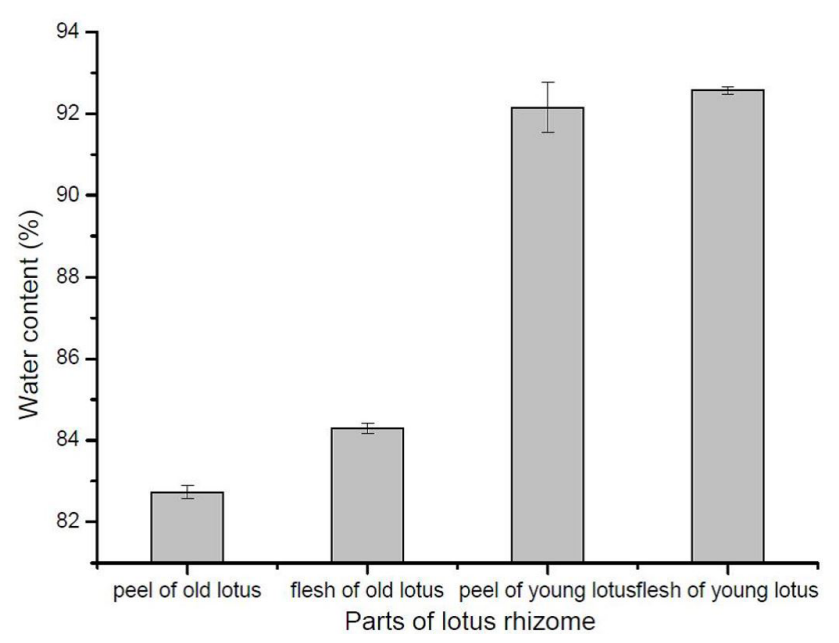

Figure 1. Water content in different parts of lotus rhizome. 


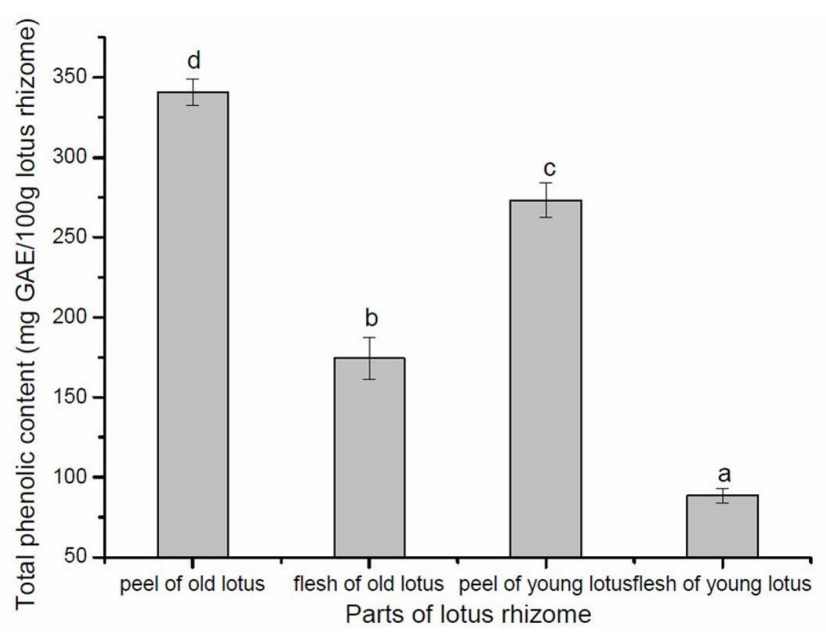

Figure 2. Total phenolic content of different parts of lotus rhizome. Values in a column with different letters were significantly different $(P<0.05)$, the same with following figures.

research results of Hu et al. (1999). These results demonstrated that the distribution of phenols in lotus rhizome in was not uniform. It was the same with other fruits and vegetables. In the apple (Limoncella), the total phenolic and flavonoid content was significantly higher in peel than in flesh (D'Abrosca et al., 2007). In the fruit of cactus (red pitaya), growing in Taiwan and Nicaragua, the total phenolic content in peel is higher than that in flesh (Wu et al., 2006). But for the persimmon (Diospyros kaki L.), the total phenolic and flavonoid content in peel is lower than that in flesh (Maisuthisakul et al., 2007).

\subsection{FRAP value of different parts of lotus rhizome}

As shown in Figure 3, the FRAP value of different parts of lotus rhizome was significantly different, and the FRAP value of lotus rhizome peel was higher than that of flesh. This was consistent with the results of Guo et al's study (2003) which showed that, in 28 fruits except kumquat determined by FRAP assay, the fruit peel demonstrated a higher antioxidant activity than fruit flesh. The mature tissue (old lotus) possessed a higher antioxidant activity than immature tissue (young lotus) both in peel and flesh. There was a positive correlation between the antioxidant activity and the total phenolic content in different parts of lotus rhizome $\left(\mathrm{R}^{2}=0.8781\right)$. This indicated that the phenols in lotus rhizome played an important role in antioxidation.

\subsection{DPPH free radical scavenging activity of different extracts}

DPPH radical scavenging by antioxidant is attributable to their hydrogen donating activity (Krings \& Berger 2001). As seen from Figure 4, the lotus rhizome peel had a higher DPPH radical scavenging activity than flesh, and the old lotus rhizome had a higher DPPH radical scavenging activity than young lotus rhizome. The order of DPPH inhibition of four parts of lotus rhizome was the same with that of FRAP, and the DPPH radical scavenging activity was significantly positive correlated

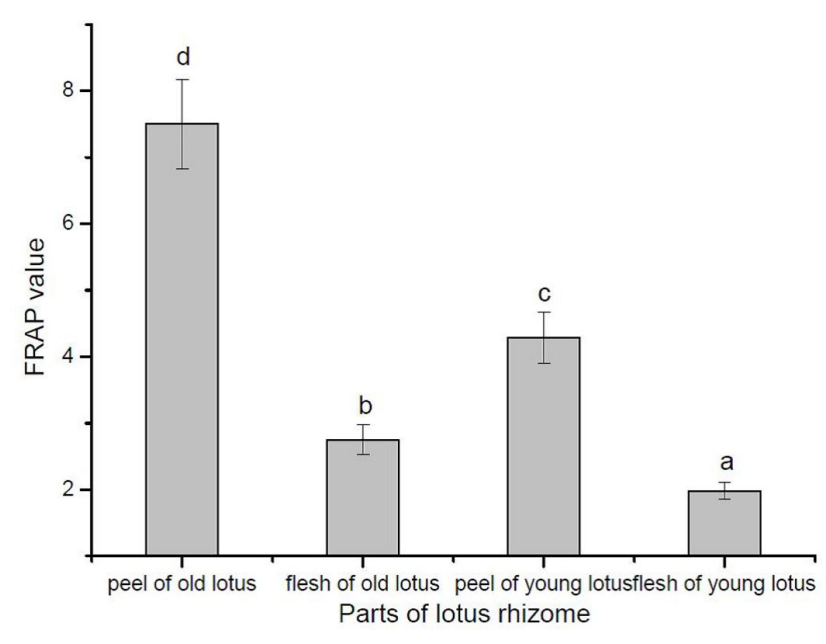

Figure 3. FRAP value of different parts of lotus rhizome.

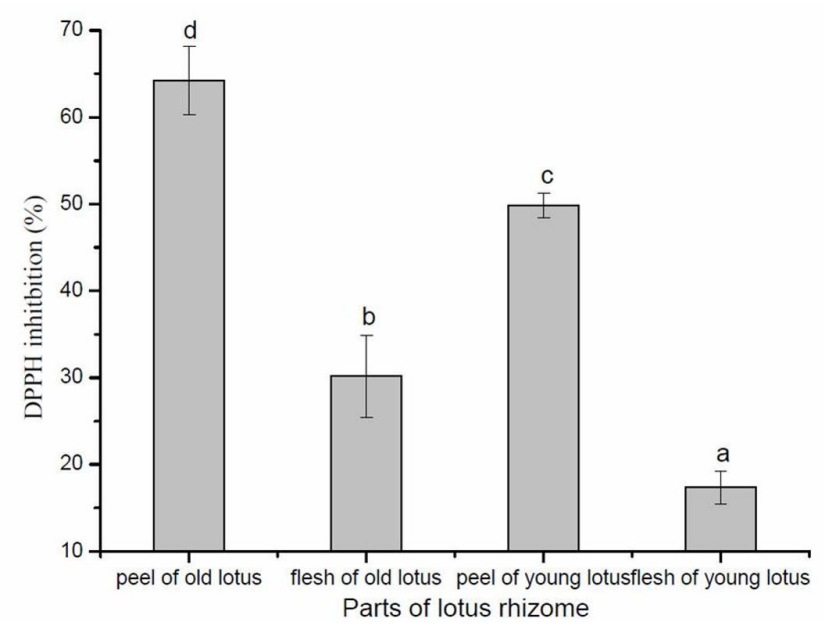

Figure 4. DPPH radical scavenging activity of different parts of lotus rhizome.

with the total phenolic content $\left(\mathrm{R}^{2}=0.9946\right)$. The results were in agreement with the pervious results of study from $\mathrm{Wu}$ et al. (2006) and D’Abrosca et al. (2007).

\subsection{Antioxidant activity determined by $\beta$-carotene bleaching method}

Antioxidant activity was determined by measuring the inhibition of volatile organic compounds and the conjugated diene hydroperoxides arising from linoleic acid oxidation. Results were shown in Figure 5. It was clear that all parts of lotus rhizome inhibited antioxidant activity against $\beta$-carotene-linoleic acid. The order of antioxidant activity of four parts of lotus rhizome was the same with the DPPH free radical scavenging activity. In addition, The AAC value was significantly positively correlated with the total phenolic content, FRAP value and DPPH inhibition $\left(R^{2}=0.9619,0.8823,0.9482\right.$, respectively). 


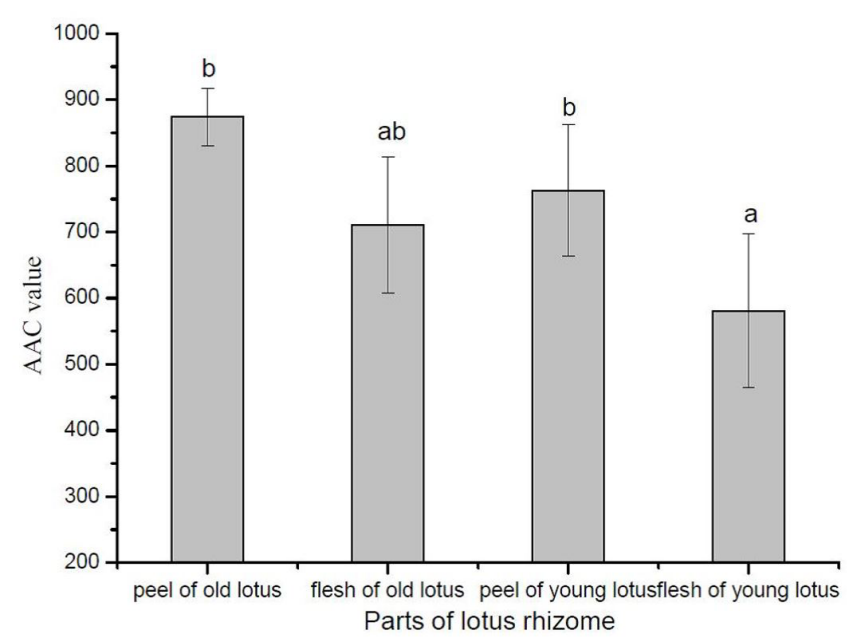

Figure 5. Antioxidant activities of different parts of lotus rhizome by $\beta$-carotene bleaching method.

\section{Conclusion}

There is a significant difference in total phenolic content and antioxidant activity between any two of four parts of lotus rhizome. The order of total phenolic content and antioxidant activity in different parts of lotus rhizome is as follows: peel of old lotus rhizome $>$ peel of young lotus rhizome $>$ flesh of old lotus rhizome $>$ flesh of young lotus rhizome. The total phenol content is significantly positively correlated with the antioxidant activity in different parts of lotus rhizome. This study has provided a basis for further exploring the antioxidant components in lotus rhizome.

\section{References}

Bensky, D., Clavey, S., \& Stoger, E. (2004). Chinese herbal medicine: materia medica (3rd ed., pp. 193-194). Seattle: Eastland Press Inc.

Benzie, I. F. F., \& Strain, J. J. (1996). The ferric reducing ability of plasma (FRAP) as a measure of "antioxidant power": the FRAP assay. Analytical Biochemistry, 239(1), 70-76. http://dx.doi.org/10.1006/ abio.1996.0292. PMid:8660627.

Chopra, R. N., Nayar, S. L., \& Chopra, I. C. (1956). Glossary of Indian Medicinal Plants (pp. 174). New Delhi: CSIR.

D’Abrosca, B., Pacifico, S., Cefarelli, G., Mastellone, C., \& Fiorentino, A. (2007). 'Limoncella' apple, an Italian apple cultivar: Phenolic and flavonoid contents and antioxidant activity. Food Chemistry, 104(4), 1333-1337. http://dx.doi.org/10.1016/j.foodchem.2007.01.073.

Guo, C. J., Wei, J. Y., Yang, J. J., Li, Y. F., Xu, J., \& Jiang, Y. G. (2003). Comparison and study on antioxidant activity of 66 kinds of vegetables and fruits. Acta Nutrimenta Sinica, 25(2), 203-207.
Hu, M., \& Skibsted, L. H. (2002). Antioxidative capacity of rhizome extract and rhizome knot extract of edible lotus (Nelumbo nucifera). Food Chemistry, 76(3), 327-333. http://dx.doi.org/10.1016/S03088146(01)00280-1.

Hu, X. D., Lu, L. M., \& Xie, B. J. (1999). The study of enzymatic browning of lotus root. Jiangsu Food and Fermentation, 32(2), 1-4.

Kashiwada, Y., Aoshima, A., Ikeshiro, Y., Chen, Y. P., Furukawa, H., Itoigawa, M., Fujioka, T., Mihashi, K., Cosentino, L. M., Morrisnatschkeg, S. L., \& Lee, K. H. (2005). Anti-HIV benzylisoquinoline alkaloids and flavonoids from leaves of Nelumbo nucifera, and structure-activity correlations with related alkaloids. Bioorganic \& Medicinal Chemistry Letters, 13(2), 443-448. http://dx.doi. org/10.1016/j.bmc.2004.10.020. PMid:15598565.

Krings, U., \& Berger, R. G. (2001). Antioxidant activity of some roasted foods. Food Chemistry, 72(2), 223-229. http://dx.doi.org/10.1016/ S0308-8146(00)00226-0.

Liu, C. P., Tsai, W. J., Lin, Y. L., Liao, J. F., Chen, C. F., \& Kuo, Y. C. (2004). The extracts from Nelumbo nucifera suppress cell cycle progression, cytokine genes expression, and cell proliferation in human peripheral blood mononuclear cells. Life Sciences, 75(6), 699-716. http://dx.doi. org/10.1016/j.lfs.2004.01.019. PMid:15172179.

Maisuthisakul, P., Suttajit, M., \& Pongsawatmanit, R. (2007). Assessment of phenolic content and free radical-scavenging capacity of some Thai indigenous plants. Food Chemistry, 100(4), 1409-1418. http:// dx.doi.org/10.1016/j.foodchem.2005.11.032.

Moreno, S. C., Larrauri, J. A., \& Saura-calixto, F. (1998). A procedure to measure the antiradical efficiency of polyphenols. Journal of Food Agriculture and Environment, 76(2), 270-276. http://dx.doi.org/10.1002/ (SICI)1097-0010(199802)76:2<270::AID-JSFA945>3.3.CO;2-0.

Moure, A., Franco, D., Sineiro, J., Dominguez, H., Nunez, M. J., \& Lema, J. M. (2000). Evaluation of extracts from Gevuina avellana hulls as antioxidants. Journal of Agricultural and Food Chemistry, 48(9), 3890-3897. http://dx.doi.org/10.1021/jf000048w. PMid:10995287.

Ono, Y., Hattori, E., Fukaya, Y., Imai, S., \& Ohizum, Y. (2006). Antiobesity effect of Nelumbo nucifera leaves extract in mice and rats. Journal of Ethnopharmacology, 106(2), 238-244. http://dx.doi. org/10.1016/j.jep.2005.12.036. PMid:16495025.

Slinkard, K., \& Singleton, V. L. (1997). Total phenol analyses: automation and comparison with manual methods. American Journal of Enology and Viticulture, 28(1), 49-55.

Wang, Q. Z., Pen, G. H., Jin, Y., Li, J., \& Yan, S. L. (2004). Extraction of polyphenol from lotus roots and its enzymatic browning substrate. Journal of Analytical Science, 20(1), 38-40.

Wu, L. C., Hsu, H. W., Chen, Y. C., Chiu, C.-C., Lin, Y.-I., \& Ho, J. A. (2006). Antioxidant and antiproliferative activities of red pitaya. Food Chemistry, 95(2), 319-327. http://dx.doi.org/10.1016/j. foodchem.2005.01.002.

Yang, D. M., Wang, Q. S., Ke, L. Q., Jiang, J. M., \& Ying, T. J. (2007). Antioxidant activities of various extracts of lotus (Nelumbo nuficera Gaertn) rhizome. Asia Pacific Journal of Clinical Nutrition, 16(Suppl 1), 158-163. PMid:17392096. 